\title{
The changes of physical activity of Mongolian adults in China and the influencing factors of their social psychology.
}

\author{
Hua Cui*, Chao Wu, Yanjin Han, Shaojun LV \\ Wushu College, Beijing Sport University, Beijing, PR China
}

\begin{abstract}
With the continuous improvement of people's living standard, the health care of the ethnic minorities in China, such as Inner Mongolia has been concerned. This paper, studies the changes of physical activity and the socio-psychological factors of Mongolian adults, through the FIT model. The study analyses the physical activity of majority of the Inner Mongolia adults and the conclusion was drawn. Physical activity is one of the important risk factor for wide spectrum of diseases and it was significantly affected by the economic level and other factors.
\end{abstract}

Keywords: Mongolian adults, Physical activity, Change stage, Social psychology.

Accepted on May 24, 2017

\section{Introduction}

With the development of economy and science and technology, people's living standards continue to improve, and become more and more convenient. This has drastically increased the Inactivity in adults thus leading to chronic diseases [1]. Heath et al. have pointed out that with the improvement of vehicle and road construction, people's physical activity time has drastically reduced, thus leads to the incidence of a variety of diseases [2]. According to the survey of the status quo of China's mass sports in recent years, the participation of young people aged 20-26 is not optimistic [3]. Li et al. states that Inner Mangolian ethnic groups constitutes about $96 \%$ of countries population, thus the state of health is of this group should be considered as a national concern [4]. However, due to the living habits the Inner Mongolia ethnic groups generally face obesity and related health issues. This paper attempts to put forward the research on the changes of physical activity and social psychological factors of Mongolian Adults in China. The study results will help the Inner Mongolia adults to improve their physical quality and reduce the incidence of disease.

\section{State of the Art}

\section{The present situation of physical activities of Mongolian adults in China}

China is a country with many ethnic groups, so the minority nationalities in the integration of the family also retain its own national characteristics of customs and habits. The Inner Mongolian adult's generally follow static activities in their daily life. Chen et al. have investigated the obesity rate of Inner Mongolia adults and the study found that $13 \%$ of Inner Mongolia's men and women were obese, and the annual rate of increase was higher than the national average growth rate of $10.2 \%$ [5]. Otgontuya et al. has pointed out that the increase in the rate of obesity in Inner Mongolia and its resident's lifestyle and customs have a great relationship [6]. Another important reason is the lack of physical activity in Inner Mongolia as shown in Figure 1.

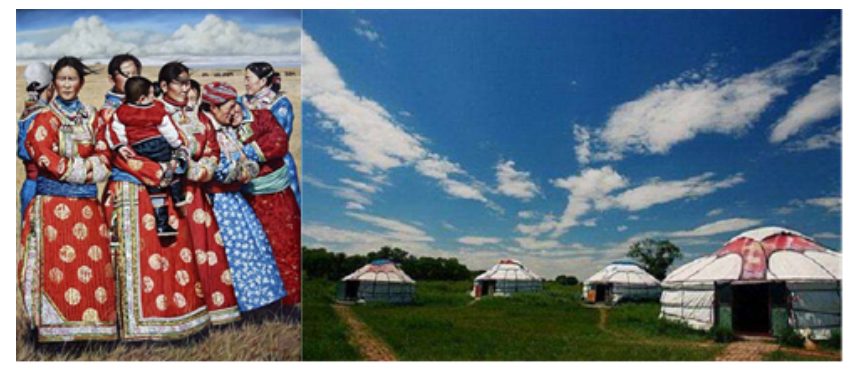

Figure 1. Mongolian adults and live scenes.

\section{Methodology}

\section{The theory and current situation of adult physical activity}

People's physical activity is a complex behavior that will be influenced by many factors such as their own physical, psychological and social, and external environment [7]. According to the current study, the understanding of physical activity can be used to explain and predict the content of the body, including the following four types:

- The healthy belief model.

- The theory of planned behavior is established on the basis of rationality.

- Self-determination theory model.

- Theory of health behavior process. 


\section{A study on the changes of physical activities of Mongolian adults in China and the models and experiments of social psychological factors}

Combined with the above analysis, the most suitable model is the FIT model. In the FIT model, there are four elements to promote the health of the body. In the course of the study, it was found that the variables of physical activity were seven variables. In this paper, it is necessary to compare the social and psychological variables with the FIT model at the adjacent stage [8]. Therefore, this paper makes assumptions about the changes in the physical activity of Mongolian adults and their social psychological factors as follows:

Subjective obstacles: $N C>C=P>E>M, P>F>M$

Self-efficacy: $N C=C=P<E<M, P<F<M$

Outcome expectation: $N C=C=P=E=M, P=F=M$

Body concept: $N C<C=P=E<M, P=F<M$

Activity plan: $N C=C=P=E<M, P<F<M$

Emotional attitude: $\mathrm{P}=\mathrm{E}<\mathrm{M}, \mathrm{P}>\mathrm{F}, \mathrm{F}<\mathrm{M}$

Internal motivation: $P<E<M, P<F<M$

In addition, we must take into account the activities of Mongolian adults and social support factors, it is necessary to assume another three factors, namely:

Activity environmental importance assessment: $P=E=M$, $P=F=M$

Emotional experience: $E<M, F<M$

Social support: $N C<C<P=E=M, P=F<M$

Among them, $\mathrm{NC}=$ prior period, $\mathrm{C}=$ period of consideration, $\mathrm{P}=$ preparation period, $\mathrm{E}=$ exploratory period, $\mathrm{F}=$ fluctuation period, $\mathrm{M}=$ retention period.

\section{Result Analysis and Discussion}

This study uses the FIT model to analyse the factors affecting the stage of physical activity of Mongolian Adults in our country and the influence of social psychology. As shown in Table 1, social psychological factors are related to support of the paired comparison in adjacent stages.

Table 1. The results of paired comparison and support of social psychological factors in adjacent stages.

\begin{tabular}{|c|c|c|}
\hline $\begin{array}{l}\text { Social psychological } \\
\text { factors }\end{array}$ & $\begin{array}{l}\text { The hypothesis of } \\
\text { paired comparison in } \\
\text { adjacent phases }\end{array}$ & $\begin{array}{l}\text { Consistent with the } \\
\text { findings of the study }\end{array}$ \\
\hline Subjective obstacles & $N C>C=P>E>M, P>F>M$ & $N C=C, F>M$ \\
\hline Self-efficacy & $N C=C=P<E<M, P<F<M$ & $N C=C, P=E, E<M, F<M$ \\
\hline Outcome expectation & $N C=C=P=E=M, P=F=M$ & $C=P, P=E$ \\
\hline Emotional attitude & $P=E<M, P>F, F<M$ & $N C<C=P, E=M$ \\
\hline Body concept & $N C<C=P<E=M, P=F<M$ & $N C=C=P, E=M$ \\
\hline Activity plan & $N C=C=P=E<M, P<F<M$ & $N C=C=P, E=M$ \\
\hline Internal motivation & $P<E<M, P<F<M$ & $E=M$ \\
\hline $\begin{array}{l}\text { Activity environmental } \\
\text { importance assessment }\end{array}$ & $P=E=M, P=F=M$ & - \\
\hline $\begin{array}{l}\text { Emotional experience of } \\
\text { environment }\end{array}$ & $E<M, F<M$ & $E<M, F<M$ \\
\hline social support & $N C<C<P=E=M, P=F<M$ & $E=M, F<M$ \\
\hline $\begin{array}{l}\text { The ratio of the number } \\
\text { of supported hypotheses } \\
\text { to the total number of } \\
\text { hypotheses }\end{array}$ & - & $22 / 37=59.50 \%$ \\
\hline
\end{tabular}

In addition, Table 2 shows the influence of the adult sex, age, educational level, economic status and physical activity behavior in frequency distribution and percentage of adults in Inner Mongolia.

The data in the Table 2 shows the gender, age, education level, economic status and stage distribution of Inner Mongolia adults. The distribution of the various stages can be seen, in the table. The adult physical activity in Inner Mongolia is considered in the most of its stage, and in the preparation period of the least.

Table 2. Frequency distribution and percentage of adult sex, age, educational level, economic status and physical activity in Inner Mongolia.

\begin{tabular}{|c|c|c|c|c|c|c|c|c|}
\hline \multicolumn{9}{|c|}{ Physical activity behavior stage $\mathrm{N}(\%)$} \\
\hline & & $\begin{array}{l}\text { Pre-consideration } \\
\text { period }\end{array}$ & $\begin{array}{l}\text { Consideration } \\
\text { period }\end{array}$ & $\begin{array}{l}\text { Preparation } \\
\text { period }\end{array}$ & $\begin{array}{l}\text { Exploratory } \\
\text { period }\end{array}$ & $\begin{array}{l}\text { Fluctuation } \\
\text { period }\end{array}$ & Shelf life & Total \\
\hline \multirow[t]{4}{*}{ Gender } & Male & 46 & 79 & 28 & 60 & 68 & 62 & 343 \\
\hline & & 13.4 & 23.0 & 8.16 & 17.5 & 19.8 & 18.1 & - \\
\hline & Female & 38 & 96 & 27 & 78 & 38 & 42 & 319 \\
\hline & & 11.9 & 30.1 & 8.5 & 24.5 & 11.9 & 13.2 & - \\
\hline \multirow[t]{3}{*}{ Age } & $27-40$ y old & 57 & 132 & 41 & 79 & 71 & 65 & 445 \\
\hline & & 12.8 & 29.7 & 9.2 & 17.8 & 16.0 & 14.6 & - \\
\hline & $41-55$ y old & 27 & 54 & 12 & 52 & 24 & 16 & 185 \\
\hline
\end{tabular}




\begin{tabular}{|c|c|c|c|c|c|c|c|c|}
\hline & & 14.6 & 29.2 & 6.5 & 28.1 & 13.0 & 8.6 & - \\
\hline \multirow{4}{*}{$\begin{array}{l}\text { Education } \\
\text { level }\end{array}$} & \multirow{2}{*}{$\begin{array}{l}\text { High school } \\
\text { and below }\end{array}$} & 65 & 125 & 14 & 56 & 24 & 13 & 297 \\
\hline & & 21.9 & 42.1 & 4.7 & 18.9 & 8.1 & 4.4 & - \\
\hline & \multirow{2}{*}{$\begin{array}{l}\text { University and } \\
\text { above }\end{array}$} & 26 & 61 & 34 & 89 & 84 & 87 & 381 \\
\hline & & 6.8 & 16.0 & 8.9 & 23.4 & 22.0 & 22.8 & - \\
\hline \multirow{4}{*}{$\begin{array}{l}\text { Economic } \\
\text { status }\end{array}$} & \multirow{2}{*}{$\begin{array}{l}\text { Less } \\
50,000\end{array}$} & 74 & 115 & 41 & 75 & 56 & 61 & 422 \\
\hline & & 17.5 & 27.3 & 9.7 & 17.8 & 13.3 & 14.5 & - \\
\hline & \multirow{2}{*}{$\begin{array}{l}50,000 \\
\text { above }\end{array}$} & 13 & 64 & 14 & 67 & 47 & 46 & 251 \\
\hline & & 5.2 & 25.5 & 5.6 & 26.7 & 18.7 & 18.3 & - \\
\hline
\end{tabular}

\section{Conclusions}

As a multi-ethnic country, ethnic minority areas not only inherited the national culture, but also retained the national characteristics of the living customs. However, with the continuous development of China's economy, people's living standards continue to improve. The health of ethnic minorities has become an important concern. In this paper, the Mongolian adult physical activity changes in the stage and its social psychology influencing factors were put forward, through the FIT model. Mongolian adult's physical activity changes and social psychology impact were analysed and the findings suggest that most of the Inner Mongolia ethnic groups were considered in the stage of physical activity, and the economic situation and the level of education were affected mostly.

\section{Acknowledgement}

The study was supported by the National Key Technology Support Program of China (2012BAK21B01), University Special Fund Program for Basic Research of China (2014QN007).

\section{References}

1. Katzmarzyk PT, Gledhill N, Shephard RJ. The economic burden of physical inactivity in Canada. CMAJ 2000; 163 : 1435-1440.

2. Heath GW, Brownson RC, Kruger J, Miles R, Powell KE, Ramsey LT. The effectiveness of urban design and land use and transport policies and practices to increase physical activity: a systematic review. J Phys Activity Health 2006; 3: $55-76$.

3. Mcgannon KR. A systematic gender-based review of physical activity correlates in coronary heart disease patients. Int Rev Sport Exerc Psychol 2015; 8: 1-23.

4. Li G, Wang H, Wang K, Wang W, Dong F, Qian Y, Shan G. Prevalence, awareness, treatment, control and risk factors related to hypertension among urban adults in Inner Mongolia 2014: differences between Mongolian and Han populations. BMC Public Health 2016; 16: 294.

5. Chen J, Yi H, Liu Z. Factors associated with being overweight among Inner Mongolia medical students in China. BMJ Open 2013; 3: 003900.

6. Otgontuya D, Khor GL, Lye MS, Norhaizan ME. Obesity among Mongolian adults from urban and rural areas. Malay J Nutr 2009; 15.

7. Humpel N, Owen N, Leslie E. Environmental factors associated with adults participation in physical activity: a review. Am J Prev Med 2002; 22: 188-199.

8. Ito Y. Social influence, social psychology. Int Encyclop Soc Behav Sci 2015; 345-347.

\section{*Correspondence to}

Hua Cui

Wushu College

Beijing Sport University

PR China 